\title{
Recent advances on the study of atmosphere-land interaction observations on the Tibetan Plateau
}

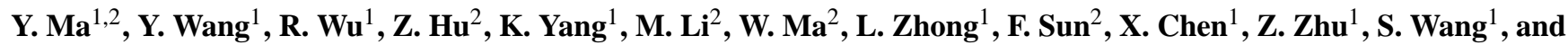 \\ H. Ishikawa ${ }^{3}$ \\ ${ }^{1}$ Key Laboratory of Tibetan Environment Changes and Land Surface Processes, Institute of Tibetan Plateau Research, \\ Chinese Academy of Sciences, Beijing 100085, China \\ ${ }^{2}$ Cold and Arid Regions Environmental and Engineering Research Institute, Chinese Academy of Sciences, \\ Lanzhou 730000, China \\ ${ }^{3}$ Disaster Prevention Research Institute, Kyoto University, Kyoto 611-0011, Japan
}

Received: 27 December 2008 - Published in Hydrol. Earth Syst. Sci. Discuss.: 24 February 2009

Revised: 22 June 2009 - Accepted: 28 June 2009 - Published: 9 July 2009

\begin{abstract}
As a unique geological and geographical unit, the Tibetan Plateau dramatically impacts the world's environment and especially controls climatic and environmental changes in China, Asia and even in the Northern Hemisphere. Tibetan Plateau, therefore, provides a field laboratory for studying global change. With support from various agencies in the People's Republic of China, a Tibetan Observation and Research Platform (TORP) is now implementing. Firstly the background of the establishment of the TORP, the establishing and monitoring plan of long-term scale (5-10 years) of the TORP has been introduced. Then the preliminary observational analysis results, such as the characteristics of land surface heat fluxes and $\mathrm{CO}_{2}$ flux partitioning (diurnal variation and inter-monthly variation etc.), the characteristics of atmospheric and soil variables, the structure of the Atmospheric Boundary Layer (ABL) and the turbulent characteristics have also been shown in this paper.
\end{abstract}

\section{Introduction}

The Tibetan Plateau, with the most prominent and complicated terrain on the globe and an elevation averaging more than $4000 \mathrm{~m}$ above mean sea level (msl), is often called the "Third Pole" because its geographic significance is akin to that of Antarctica and the Arctic (Qiu, 2008). The Tibetan Plateau dramatically impacts the world's environment and

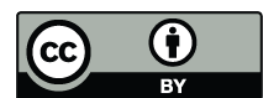

Correspondence to: $\mathrm{Y} . \mathrm{Ma}$

(ymma@itpcas.ac.cn) especially controls climatic and environmental changes in Asia and elsewhere in the Northern Hemisphere. It therefore provides a field laboratory for studying global climatic change.

The thermal effects of the giant plateau on the atmosphere greatly influence circulations over China, eastern Asia and even the globe (e.g. Ye and Gao, 1979; Ye, 1981; Yanai et al., 1992; Ye and Wu, 1998; Ma and Tsukamoto, 2002; Ma et al., 2005; Ma et al., 2006a; Ma et al., 2006a;). The plateau absorbs a large proportion of solar radiation (some of which is redistributed by cryospheric processes) and undergoes dramatic seasonal changes of surface heat and water fluxes (e.g. Ye and Gao, 1979; Zhang et al., 1988; Yanai et al., 1992; Ye and Wu, 1998; Xu et al., 2002; Ma et al., 2005; Ma et al., 2006a; Ma et al., 2006b). The lack of quantitative understanding of interactions between the land surface and atmosphere makes it difficult to understand and model the complete energy and water cycles over the Tibetan Plateau and their effects on global climate change. Therefore, the number of atmosphere-land interaction studies over the $\mathrm{Ti}$ betan Plateau has been increased in recent years. But experiments have been limited to determine the land and atmospheric parameters, and most investigations have been only in summer and at a few locations (e.g. Zhang et al., 1988; Ye and $\mathrm{Wu}, 1998$; Ma and Tsukamoto, 2002; Xu et al., 2002; Yang et al., 2004; Ma et al., 2005, 2006a, b).

Supported by Chinese Academy of Sciences, Ministry of Science and Technology of People's Republic of China, China Meteorological Administration, Ministry of Education of People's Republic of China, Tibetan Autonomous Region of China, and State Forest Administration, People's Republic

Published by Copernicus Publications on behalf of the European Geosciences Union. 


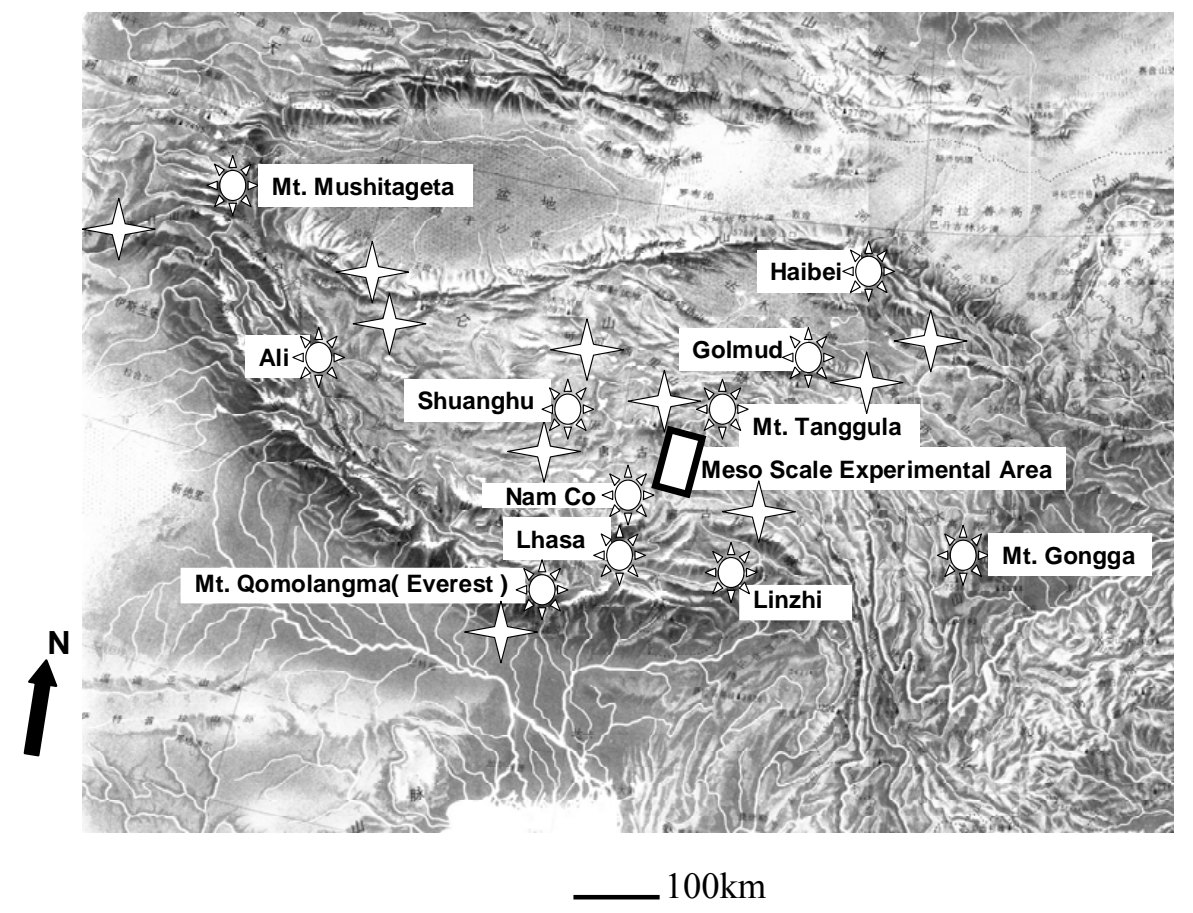

Fig. 1. The Tibetan Observation and Research Platform (TORP) for the study of atmosphere-land interaction on the Tibetan Plateau.

of China, an Tibetan Observation and Research Platform (TORP) has been established and being focused on the land surface processes and environment over the plateau, with an emphasis on atmosphere-land interaction.

The establishing and monitoring plan and the recent advances of the TORP will be introduced firstly in this paper. Then the preliminary observational analysis results, such as the characteristics of land surface heat fluxes and $\mathrm{CO}_{2}$ flux partitioning (diurnal variation, inter-monthly variation and inter-yearly variation etc.), the characteristics of atmospheric and soil variables, the structure of the Atmospheric Boundary Layer (ABL) and the turbulent characteristics will also be shown here.

\section{Tibetan Observation and Research Platform (TORP)}

The TORP is consisted of 21 comprehensive observation and research stations and 16 observational sites, of which 11 comprehensive observation and research stations and $10 \mathrm{ob}-$ servational sites are configured for the study of atmosphereland interaction (see Fig. 1). The instruments and parameters measured in the comprehensive observation and research stations and the observational sites are shown in Table 1. Three comprehensive observation and research stations (Mt. Qomolangma-Mt. Everest, Namco, and Linzhi) were established by the Institute of Tibetan Plateau Research (ITP), the Chinese Academy of Sciences (CAS) in the end of August 2005. The comprehensive observation and re- search stations of Haibei, Golmud, Lhasa and Mt. Gongga were established by other institutes of CAS around the beginning of 2000. All the established stations are working well now and have yielded a large amount of data. Ali station and Mt. Mushitageta have been established in the end of 2008. Shuanghu station and Mt. Tanggula station will be established by ITP, CAS around the end of 2012. All the 10 observational sites are just in planning now, and they will be set up around the end of 2012. It means that 11 comprehensive observation and research stations and 10 observational sites will be operating around the end of 2012 .

One of the important parts in the TORP is the mesoscale monitoring network (see Figs.1 and 2). It has already worked successfully during the Global Energy and Water cycle Experiment (GEWEX) Asian Monsoon Experiment on the Tibetan Plateau (GAME/Tibet, 1996-2000) and the Coordinated Enhanced Observing Period (CEOP) Asia-Australia Monsoon Project on the Tibetan Plateau (CAMP/Tibet, 2001-2006) (Ma et al., 2005). This monitoring network was established in the beginning of 1998 during the GAME/Tibet period and some more instruments were set up during the CAMP/Tibet period (see Fig. 2 and Table 2). It covered a $150 \mathrm{~km} \times 250 \mathrm{~km}$ area $\left(91^{\circ}-92.5^{\circ} \mathrm{E}, 30.7^{\circ}-33.3^{\circ} \mathrm{N}\right)$ and many kinds of instruments have been deployed in the network (see Fig. 2, Table 1 and Ma et al., 2005). A large amount of data has been collected during the GAME/Tibet and the CAMP/Tibet, which was the best data set so far for the study of the Tibetan Plateau hydrometeorology (Ma et al., 2005). It is better to expand the observation as long as 

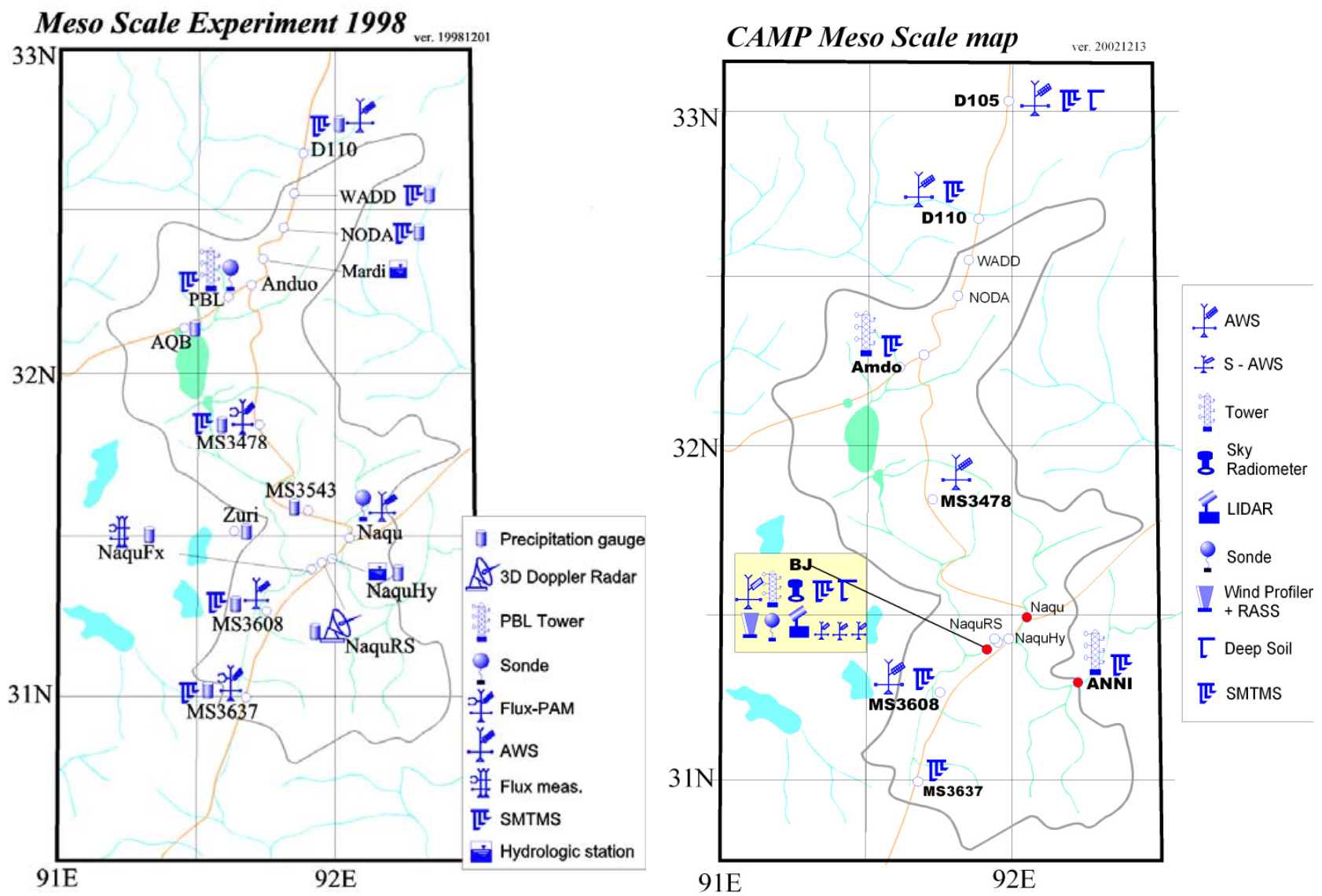

Fig. 2. The sites layout during the Global Energy and Water cycle Experiment(GEWEX) Asian Monsoon Experiment on the Tibetan Plateau (GAME/Tibet)and the Coordinated Enhanced Observing Period (CEOP) Asia-Australia Monsoon Project on the Tibetan Plateau (CAMP/Tibet).

possible for the study of atmosphere-land interaction and climatic change over the Tibetan Plateau and surrounding areas. Therefore all the instruments in the GAME/Tibet and CAMP/Tibet will be continued for long-term observations in the TORP.

The data collected by the TORP will be archived by the TORP data center in the ITP, CAS. The archived data will be available to the scientific community all over the world. Scientists can submit a proposal to the data center to apply for using data.

\section{In-situ data analysis and results over the Tibetan Plateau area}

\subsection{Land surface heat fluxes and $\mathrm{CO}_{2}$ flux}

The characteristics of the land surface heat fluxes and $\mathrm{CO}_{2}$ flux over the Tibetan Plateau area were derived by using insitu data observed from the TORP. The results show that:
1. The diurnal variations of radiation fluxes (downward and upward shortwave radiation and upward long-wave radiation) and surface heat fluxes (net radiation flux, soil heat flux, sensible heat flux and latent heat flux) over the Tibetan Plateau area are very obvious clear, and the downward shortwave radiation are obvious larger than that in other areas due to the higher elevation and clear atmosphere over the Tibetan Plateau area (e.g. Tanaka et al., 2001; Ma et al., 2003, 2005; Ma and Ma, 2006; Ishikawa et al., 2006; Li, et al., 2006a, b, c; Zhong et al., 2006., 2007a, b; Ma et al., 2007; Li et al., 2008). The surface energy budget was, however, not well closed from the observed data. This kind of "imbalances" was found not only from the ABL tower (AWS) data analysis, but also from sonic-anemometer data analysis. And the "imbalances" is larger in summer than that in winter, it is $70 \%$ in summer and $92 \%$ in winter (e.g. Tanaka et al., 2001; Ma et al., 2005; Ishikawa et al., 2006; Su et al., 2006). 
Table 1. The instruments and parameters measured in the comprehensive observation and research stations and observational sites of the TORP.

\begin{tabular}{|c|c|}
\hline Station (site) & Observation item \\
\hline $\begin{array}{l}\text { Comprehensive } \\
\text { observation and } \\
\text { research station }\end{array}$ & $\begin{array}{l}* * * 20 \text { m ABL tower (MILOS520, Vaisala Co.): wind speed, wind direction, } \\
\text { air temperature and humidity (height }(\mathrm{m}): 1.0,2.0,4.0,10.0 \text { and } 20.0) \text {, } \\
\text { surface temperature, soil heat flux (depth }(\mathrm{cm}):-10 \text { and }-20) \text {, air pressure, } \\
\text { rain intensity. } \\
\text {-Radiation measurement system(CNR-1, Kipp \& Zonen Co.): short wave } \\
\text { radiation (downward and upward), long wave radiation (downward and } \\
\text { upward). } \\
\text { ***Soil moisture and soil temperature measurement system (SMTMS): } \\
\text { Soil moisture (Trime EZ, Imko Co.) (depth }(\mathrm{cm}):-10,-20,-40,-80,-160) \text {; } \\
\text { Soil temperature (Pt100, Datamark Co.) (depth (cm): }-10,-20,-40,-80 \text {, } \\
-160) \text {. } \\
* * * G P S \text { radio-sonde system (MW21 DigiCORA III, Vaisala Co.): Profile of } \\
\text { air pressure, air temperature, relative humidity, wind speed and direction. } \\
* * * \text { Wind Profiler and RASS (LAP3000, Vaisala Co.): Profile of air } \\
\text { temperature, wind speed and direction. } \\
* * * \text { Sonic turbulent measurement system (CSAT3, Campbell Co.) and } \\
\mathrm{CO}_{2} / \mathrm{H}_{2} \mathrm{O} \text { flux measurement system (LI7500, Campbell Co.): wind speed, } \\
\text { wind direction, air temperature, relative humidity, the characteristic length } \\
\text { scales of surface layer, sensible heat flux, latent heat flux, } \mathrm{CO}_{2} / \mathrm{H}_{2} \mathrm{O} \text { flux, } \\
\text { stability parameter. }\end{array}$ \\
\hline $\begin{array}{l}\text { Observational } \\
\text { site }\end{array}$ & $\begin{array}{l}* * * 10 \text { m Automatic Weather Station (AWS) (MILOS520, Vaisala Co.): } \\
\text { wind speed, wind direction, air temperature and humidity (height }(\mathrm{m}): 1.0 \text {, } \\
5.0 \text {, and 10.0), surface temperature, soil heat flux (depth }(\mathrm{cm}):-10 \text { and }-20) \text {, } \\
\text { air pressure, rain intensity, and snow depth. } \\
\text { ***Radiation measurement system (CNR-1, Kipp \& Zonen Co.): short wave } \\
\text { radiation (downward and upward), long wave radiation (downward and } \\
\text { upward). } \\
\text { ***Soil moisture and soil temperature measurement system (SMTMS): } \\
\text { Soil moisture (Trime EZ, Imko Co.) (depth (cm): }-10,-20,-40,-80,-160) \text {; } \\
\text { Soil temperature (Pt100, Datamark Co.) (depth }(\mathrm{cm}):-10,-20,-40,-80 \text {, } \\
-160) \text {. }\end{array}$ \\
\hline
\end{tabular}

2. The diurnal variations of the turbulent fluxes are different during the dry period (pre-monsoon period) and wet period (inside monsoon period). During dry period, the daytime sensible heat flux is larger than the latent heat flux, while during the wet period, the latent heat flux is larger than the sensible heat flux due to the different land surface status between the dry and wet period (e.g. Ma et al., 2003, 2005; Li et al., 2006a; Ma and Ma, 2006).

3. The diurnal variation of momentum flux over the northern Tibetan Plateau area during the dry period is also obvious, increasing in the morning to its maximum in the afternoon, and then decreasing. While it is complex during the wet period, the daytime momentum flux is lower than that during the dry period, yet it still increases at night (Li et al., 2006a).
4. Sensible heat flux $H$ and latent heat flux $L E$ vary by less than $10 \%$ of their magnitude with height over the flat prairie area of Naqu area of the northern Tibetan Plateau. In other words, the surface layer (up to $20 \mathrm{~m}$ ) over the flat prairie area is a constant flux layer, i.e. the Monin-Obukhov similarity theory applies to this height, and energy advection at the area can be neglected, at least up to $20 \mathrm{~m}$ (Ma et al., 2005).

5. The land surface is a very strong heating source in the day time, it is a weak surface heating sink in the night, but the daily mean is strong surface heating source. The surface heating densities $\left(R_{n}\right.$ (net radiation) $-G_{0}$ (soil heat flux) or $H$ (sensible heat flux) $+L E$ (latent heat flux)) in summer are much larger than those in winter, and they reach their minimum values around January. In other words, the surface of the Tibetan Plateau is a strong heating source in summer and it is a weak heating source in winter (e.g. Ma and Tsukamoto, 2002). 
Table 2. The instruments and parameters measured in the sites of the mesoscale network of the TORP.

\begin{tabular}{|c|c|}
\hline Site & Observation item \\
\hline Amdo & $\begin{array}{l}\text { ***PBL (ABL) tower (MILOS500, Vaisala Co.): wind speed } \\
\text { (Aerobane FF-11, Ogasawara Co.) (height (m): 1.9, 6.0 and 14.1), } \\
\text { wind direction (Aerobane FF-11, Ogasawara Co.) (height (m): 14.1), } \\
\text { air temperature (HMP35D-Pt100, Vaisala Co.) and humidity (Electric } \\
\text { Capacitance, ibid Co.) (height }(\mathrm{m}): 1.55,5.65 \text { and 13.75), surface } \\
\text { temperature (MF-81, Optex Co.), soil heat flux (MF-81, EKO Co.) } \\
\text { (depth (cm): }-10 \text { and -20), air pressure (DPA21, Vaisala Co.), rain } \\
\text { intensity (RG-13, Vaisala Co.). } \\
\text { ***Radiation: downward and upward short wave radiation (CM21, } \\
\text { Kipp \& Zonen Co.), downward and upward long wave radiation } \\
\text { (Precision Infrared Radiometer, Eppley Co.) }\end{array}$ \\
\hline $\begin{array}{l}\text { Automatic Weather Station } \\
\text { (AWS) } \\
\text { (D110, MS3608) }\end{array}$ & $\begin{array}{l}\text { Wind speed and wind direction at } 6.0 \mathrm{~m} \text { (WS-942, Ogasawara Co.), air } \\
\text { temperature and humidity at } 1.5 \mathrm{~m} \text { (HMP35A, Vaisala Co.), surface } \\
\text { temperature (HR1-FL, Chino Co.), soil temperature at }-20 \mathrm{~cm} \text { (Pt-100, } \\
\text { Vaisala Co.), solar radiation (S-100, EKO Co.), air pressure (PTB100, } \\
\text { Vaisala Co.), rain intensity (RG-13, Vaisala Co.) }\end{array}$ \\
\hline $\begin{array}{l}\text { Automatic Weather Station } \\
\text { (AWS) } \\
\text { (D105, MS3478, BJ, ANNI) }\end{array}$ & $\begin{array}{l}\text { Wind speed (WS-D32, Komatsu Co.) (height (m): 10, 5, 1.0), wind } \\
\text { direction at } 10 \mathrm{~m} \text { (WS-D32, Komatsu Co.), air temperature (TS-801, } \\
\text { Okazaki Co.) and humidity (HMP-45D, Vaisala Co.) (height (m): 9.0, } \\
\text { 1.0), downward and upward short-wave radiation (CM21, Kipp \& } \\
\text { Zonen Co.), downward and upward long wave radiation (Precision } \\
\text { Infrared Radiometer, Eppley Co.), air pressure (PTB220C, Vaisala Co.), } \\
\text { surface temperature (IRt/C 1X-T50F, Exergen Co.), snow depth (SR-50, } \\
\text { Campbel Co.), precipitation (NOAH-II, ETI Co.), soil heat flux } \\
\text { (MF-81, EKO CO.) (depth (cm):-10, -20). }\end{array}$ \\
\hline $\begin{array}{l}\text { Soil moisture and soil } \\
\text { temperature suystem } \\
\text { (D105, D110, Amdo, BJ,) } \\
\text { (ANNI, MS3608, MS3637) }\end{array}$ & $\begin{array}{l}* * * \text { Soil temperature }(\mathrm{Pt} 100, \text { Datamark Co. })(\mathrm{depth}(\mathrm{cm}):-4,-20,-60, \\
-80,-100,-130,-160,-200,-279) . \\
* * * \text { Soil moisture (Trime EZ, Imko Co.) (depth }(\mathrm{cm}):-4,-20,-60,-100 \text {, } \\
-160,-258) .\end{array}$ \\
\hline $\begin{array}{l}\text { Turbulent measurement } \\
\text { (BJ) }\end{array}$ & $\begin{array}{l}\text { Sonic turbulent measurement system (DA-600, Kaijo Denki Co.) } \\
\text { and } \mathrm{CO}_{2} / \mathrm{H}_{2} \text { Oflux measurement system (LI7500, Campbell Co.): } \\
\text { wind speed, wind direction, air temperature, relative humidity, the } \\
\text { characteristic length scales of surface layer, sensible heat flux, latent } \\
\text { heat flux, } \mathrm{CO}_{2} / \mathrm{H}_{2} \mathrm{O} \text { flux, stability parameter. }\end{array}$ \\
\hline $\begin{array}{l}\text { Wind Profiler and RASS } \\
(\text { LAP3000, Vaisala Co.)(BJ) }\end{array}$ & Profile of air temperature, wind speed and direction. \\
\hline
\end{tabular}

6. The diurnal variation of $\mathrm{CO}_{2}$ flux in summer is obvious over the alpine meadow surface of Mt. Everest area. The negative $\mathrm{CO}_{2}\left(\mathrm{CO}_{2}\right.$ uptake) flux was observed from 1000 (local time) to 2100 , but positive $\mathrm{CO}_{2}$ flux (net $\mathrm{CO}_{2}$ emission) from 2200 to next $1100 . \mathrm{CO}_{2}$ flux is close to zero during the most time of the day in winter, but showed a weak net upward $\mathrm{CO}_{2}$ flux from 1600 to 2100 (e.g. Zhu et al., 2007) .

\section{The characteristics of atmospheric and soil variables}

The characteristics of the atmospheric and soil variables over the Tibetan Plateau area were derived by using in-situ data observed from the TORP. The results show that:

1. Surface albedo over the Tibetan Plateau has different values in different season (Fig. 3), it is higher in winter and spring and it is lower in summer and autumn. The different albedo values in different seasons are not only depended on the vegetation coverage, but also depended on the snow cover. The grass is growing in summer and autumn, but it becomes dry and very few in spring and 


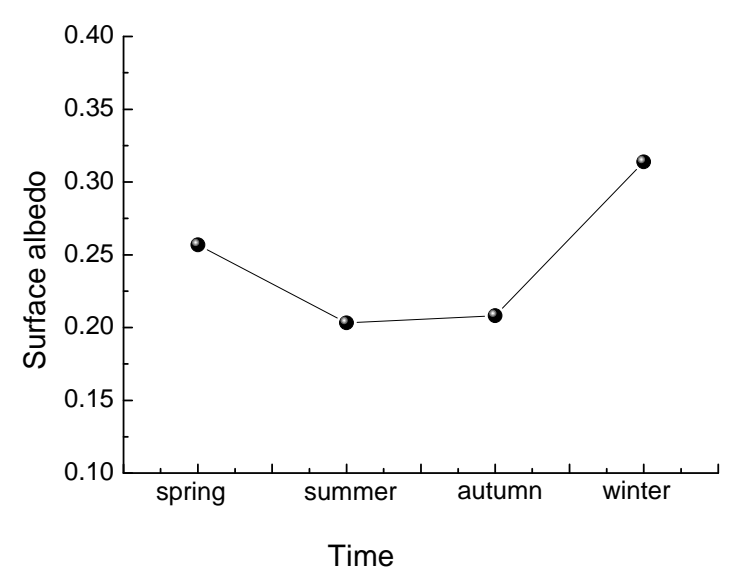

Fig. 3. The surface albedo variation over the Tibetan Plateau.

winter, and the land surfaces of the stations (sites) are always covered with the snow in winter. Data used in Fig. 3 is hourly average values over seasons from six stations (sites) shown in the literature (Ma et al., 2005; Ma and Ma, 2006; Li et al., 2007; Zhong et al., 2007b). The six stations (sites) are D105, Amdo, MS3478, BJ and ANNI (Fig. 2) and Mt. Qomolangma Station. The land surfaces of Amdo, MS3478, BJ and ANNI are covered with plateau grassy marshland and D105 and Mt. Qomolangma Station are covered with sparseness meadow.

2. The aerodynamic roughness length $z_{0 \mathrm{~m}}$ and the thermodynamic roughness length $z_{0 \mathrm{~h}}$ are significantly different over the different land surfaces of the Tibetan Plateau. $z_{0 h}$ is one magnitude smaller than $z_{0 \mathrm{~m}}$. It means that both the aerodynamic and thermodynamic characteristics of the land surface have effects on $z_{0 \mathrm{~m}}$ and $z_{0 \mathrm{~h}}$ (e.g. Ma et al., 2002a; Yang et al., 2003, 2008; Ma et al., 2008).

3. The excess resistance to heat transfer, $k B^{-1}$, has obvious diurnal variation over the Tibetan Plateau, i.e. the $k B^{-1}$ values derived by other researchers in other areas cannot been used directly in the numerical solutions and the procedures of satellite remote sensing parameterization over the Tibetan Plateau area, the different values of $k B^{-1}$ should be used in different time of a day (e.g. Ma et al., 2002a; Yang et al., 2003, 2008; Ma et al., 2008).

4. The variation of daily average ground temperature above $10 \mathrm{~cm}$ can be showed as a sine curve. The yearly maximum temperature is in July and August. The phase of soil temperature variation in deeper layer is lagged behind that of the shallower layer. The cooling of the soil is quite slow. However, the warming of the soil is fast in spring and summer. Such phenomena may be associated with the feedback processes of snow cover, albedo, long wave radiation and the heat of condensation. The change of yearly climate can be reflected in the depth of $40 \mathrm{~cm}$ at least. The variations of daily mean soil moisture at different depths have no pronounced change. The variations of monthly mean soil moisture in different depths change distinctly. Soil moisture is dependent on summer precipitation (e.g. Zhao et al., 2006; Li et al., 2007; Zhong et al., 2007b; Chen et al., 2008).

\subsection{The structure of the Atmospheric Boundary Layer}

The structure of the Atmospheric Boundary Layer (ABL) is analyzed by using the data observed from ABL tower, GPS radio-sonde system and Wind Profiler and RASS from the TORP. The results show that:

1. The plateau ABL can extend to heights of almost $3 \mathrm{~km}$ above the ground surface in Naqu area of the northern Tibetan Plateau, and is characterized by a well-mixed layer of potential temperature. The ABL height during the dry season is higher than that in the wet season. The energy budget in the ABL indicates that the sensible heat is the dominant energy for sustaining the ABL growth, and radiation also plays a significant role, but the rain evaporative cooling below the wet convection suppresses ABL development. The ABL evolution is strongly associated with the convective activities. The convection not only efficiently exchanges the quantities between the near-surface layer and the upper layer, but also enhances the air entrainment near the top of the ABL (e.g. Yang et al., 2004; Zuo et al., 2005; Li et al., 2006c; Chen et al., 2007; Wang and Ma, 2008).

2. The convection over the Tibetan Plateau evolves from dry shallow convection in the morning to wet deep convection in the afternoon. The shallow convection is organized, and its major wavelength is controlled by mesoscale hills. The deep convection is not very regular. Both nonlinear scale interactions and latent heat release from convection may play significant roles in the development of the deep convection. However, the deep convection near mountains is related to an interactive process between mountain-valley circulations and rain evaporative cooling. The mountain-valley circulations in the afternoon can be either upslope or down slope (e.g. Yang et al., 2004; Zuo et al., 2005).

3. The vertical gradients of potential temperature and humidity in the ABL of the Tibetan Plateau have an obvious sudden change in the middle of June. It indicates that the Asian monsoon comes around that period (e.g. Sun et al., 2006, 2007; Sun and Ma, 2007).

4. Clear glacier wind appears around the Mt. Everest area. The mountainous landform and the glacier environment 
of Mt. Everest region had a major influence on the lower $\mathrm{ABL}$, and the strong wind that takes place in late afternoon which was caused probably by the glacier wind from the Mt. Everest (e.g. Sun et al., 2006., 2007; Sun and Ma, 2007).

5. The ABL height has obvious diurnal variation over the Mt. Everest area (Fig. 4). It means that when the sun rises at around 10:00 LT (Local Time) in the morning, ABL height increase with the increasing of solar altitude angle, and the maximum value appears at about 15:00 LT, then it decrease with the decreasing of solar altitude angle. Data used in Fig. 4 is hourly average values from the daily radio sounding measurements from 23 March to 29 May 2005 in Mt. Qomolangma Station.

\subsection{The characteristics of the atmospheric turbulent structure}

The characteristics of the atmospheric turbulent structure are analyzed by using the data observed from the sonic turbulent measurement system from the TORP. The results show that:

1. In general, turbulence statistics over the flat prairie on the northern Tibetan Plateau show similar results to those reported in the literature (e.g. Wang and Mitsuta, 1991) from other sites. In other words, the normalized variance of the vertical wind was in better agreement with the law of Monin and Obukhov similarity theory than the horizontal wind. The normalized variance of 3-D wind speed obeys the power law of 1/3 (Monin and Obukhov, 1954). The normalized variance of wind speed means that is normalized by the wind speed, and it is same as temperature and specific humidity. The normalized variance of temperature and specific humidity satisfies the power law of $-1 / 3$ only in unstable conditions, it shows a very big discrepancy under neutral stratification, but this is reduced with the increase of stability under stable conditions (e.g. Ma et al. 2002b; Choi et al., 2004; Hong et al., 2004; Asanuma et al., 2005; Li et al., 2006a). However, further scrutiny of turbulence data from different heights and (co)spectra analysis revealed a) height dependence of the turbulent statistics of vertical wind velocity; b) a spectral gap with the absence of $k^{-1}$ power law in mid frequencies in the spectra of lateral wind velocity; and c) the deviation of heat flux co-spectra in low frequencies from MoninObukhov theory (e.g. Choi et al., 2004; Hong et al., 2004; Asanuma et al., 2005). It means that the turbulent observation height and surrounding environment have impact on the spectra of wind velocity and heat flux cospectra. These results not only provide the evidence of interactions between active and inactive turbulence but also shed light on different views on the fundamental mechanism of such interactions in the atmospheric surface layer.

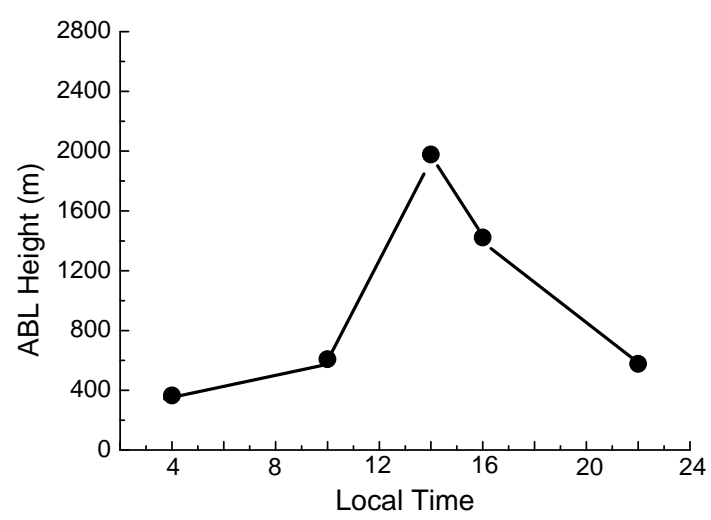

Fig. 4. The diurnal variation of the ABL height over the Mt. Everest area.

2. The analysis of averaged spectra and co-spectra under near neutral stratification over the Mt. Everest area (the representative of Himalaya) revealed that low frequency perturbations have a large influence on the variance of all wind components, but mid frequency perturbations have only influence on the variances of vertical wind components and also alter the co-spectra of momentum and sensible heat flux under near neutral stratification. The spectrum of the horizontal wind speed is comparable to universal spectra. The middle frequency perturbations occur as brief intermittent events and result in downward entrainment of ambient air thereby producing enhanced downward sensible heat fluxes and downward as well as upward momentum fluxes with various magnitudes and timescales. The perturbation of low and mid frequencies is introduced. Spectral power of $w$ spectrum reduced results from glacier wind on the outer layer. When the wind direction was between $180^{\circ}$ and $225^{\circ}$, increased spectral power of $u v$ and $w$ spectrum in low frequency domain and reduced spectral power of $w$ spectrum in mid frequency domain results from glacier wind on the outer layer. The $u w$ co-spectra and $T w$ co-spectra is minus in the mid and high frequency due to downward moment flux and heat flux respectively (e.g. Liu et al., 2007).

3. The normalized deviation of 3-D wind speed and temperature and specific humidity agree with the literature (e.g. Wang and Mitsuta, 1991) over the Mt. Everest area. In neutral condition, relations between non-dimensional wind speed components and $z / L$ follow the " $1 / 3$ power law" (Monin and Obukhov, 1954), but the coefficients are different from those in other place (e.g. Li et al., 2006a) in the Tibetan Plateau due to its special terrains (e.g. Zhong et al., 2006; Liu et al., 2007; Zhong et al., 2007a). 


\section{Concluding remarks}

In this paper, the Tibetan Observation and Research Platform (TORP) is introduced and some preliminary observational results, such as the characteristics of land surface heat fluxes and $\mathrm{CO}_{2}$ flux partitioning (diurnal variation and intermonthly variation etc.), the characteristics of atmospheric and soil variables, the ABL structure and the turbulent characteristics have also been shown by using the in-situ data observed from TORP.

All analysis and results shown in this paper is just preliminary. In order to understand the impact of the Tibetan Plateau on the weather forecast and climatic change prediction over China, eastern Asia and even the globe, the deep in-situ data analysis has to be done in the future research.

All the results in this paper are acquired from the datasets observed in the Tibetan Plateau. In order to extend them to a broader perspective, the results gotten in the Tibetan Plateau have to be compared to those over similar landscape types, i.e. arctic, sub-arctic and alpine etc. All these researches will have to be done by using the in-situ data observed from the TORP in the days to come.

Acknowledgements. This paper was under the auspices of the National Natural Science Foundation of China (40825015), Innovation Projects of the Chinese Academy of Sciences (KZCX2-YW-Q1101), the Chinese National Key Programme for Developing Basic Sciences (2005CB422003), EU-FP7 project "CEOP-AEGIS" (212921). The authors thank all the colleagues for their very hard work in the construction and the field work of the TORP.

Edited by: Z. Su

\section{References}

Asanuma, J., Ishikawa H., Tamagawa, I., Ma, Y., Hayashi, T., Qi, Y., and Wang, J.: Application of the band-pass covariance technique to portable flux measurements over the Tibetan Plateau, Water Resour. Res., 41, W09407, doi:10.1029/2005WR003954, 2005.

Chen, X., Ma, Y., Sun, F., Li, M., and Wang, S.: The rainy season character of tropsphere at Mt. Qomolangma Region, Plateau Meteorology, 26(6), 1280-1286, 2007.

Chen, X., Ma, Y., Li, M., Ma, W., and Wang, H.: Analyses on near surface layer atmospheric characteristics and soil features in northern Tibetan Plateau, Plateau Meteorology, 27(5), 941-948, 2008.

Choi, T., Hong, J., Kim, J., Lee, H., Asanuma, J., Ishikawa, H., Tsukamoto, O., Gao, Z., Ma, Y., Ueno, K., Wang, J., Koike, T., and Yasunari, T.: Turbulent exchange of heat, water vapor, and momentum over a Tibetan prairie by eddy covariance and flux variance measurements, J. Geophys. Res., 109, D21106, doi:10.1029/2004JD004767, 2004.

Hong, J., Choi, T., and Kim, J.: Turbulence structures in the nearneutral surface layer on the Tibetan Plateau, Geophys. Res. Lett., 31, L15106, doi:10.1029/2004GL019935, 2004.
Ishikawa, H., Tanaka, K., Oku, Y., Ma, Y., Hu, Z., Li, M., and Ma, W.: Surface flux estimation using in situ measurement, Adv. Earth Sci., 21(12), 1237-1243, 2006.

Li, M., Ma, Y., Ma, W., Hu, Z., Ishikawa, H., Su, Z., and Sun, F.: Analysis of turbulence characteristics over the northern Tibetan Plateau area, Adv. Atmos. Sci., 23(4), 579-585, 2006 a.

Li, M., Ma, Y., Zhong, L., and Lu, S.: Preliminary analysis on near surface radiation budget in the region of Mt. Qomolangma in April and May 2005, Plateau Meteorology, 25(6), 1008-1013, 2006b.

Li, M., Dai, Y., Ma, Y., Zhong, L., and Lu, S.: Analysis on structure of atmospheric boundary layer and energy exchange of surface layer over mount Qomolangma region, Plateau Meteorology, 25(5), 807-813, $2006 \mathrm{c}$.

Li, M., Ma, Y., Ishikawa, H., Ma, W., Sun, F., Wang, Y., and Zhu, Z.: Characteristics of micrometeorological elements near surface and soil on the northern slope of Mt. Qomolangma area, Plateau Meteorology, 26(6), 1263-1268, 2007.

Li, M., Ma, Y., Wang, Y., Sun, L., Zhao, Y., and Lu, Y.: Characteristics of micrometeorology and exchange of surface energy in the Namco region, Plateau Meteorology, 27(4), 727-732, 2008.

Liu, H., Feng, J., Zou, H., and Li, A.: Turbulent Characteristics of the Surface Layer in Rongbuk Valley on the Northern Slope of Mt. Qomolangma., Plateau Meteorology, 26(6), 1151-1161, 2007.

Ma, W. and Ma, Y.: The annual variations on land surface energy in the northern Tibetan Plateau, Environ. Geol., 50, 645-650, doi:10.1007/s00254-006-0238-9, 2006.

Ma, W., Dai, Y., Ma, Y., Sun, F., Li, M., Zhong, L., and Wang, Y.: Seasonal variations of land surface radiation budget and energy on northern slope of Mt.Qomolangma area, Plateau Meteorology, 26(6), 1237-1243, 2007.

Ma, Y. and Tsukamoto, O.: Combining satellite remote sensing with field observations for land surface heat fluxes over inhomogeneous landscape, China Meteorological Press, Beijing, China, 172 pp., 2002.

Ma, Y., Tsukamoto, O., Wang, J., Ishikawa, H., and Tamagawa, I.: Analysis of aerodynamic and thermodynamic parameters over the grassy marshland surface of Tibetan Plateau, Prog. Nat. Sci., 12(1), 36-40, 2002a.

Ma, Y., Ma, W., Hu, Z., Li, M., Wang, J., Ishikawa, H., and Tsukamoto, O.: Similarity analysis of atmospheric turbulent intensity over grassland surface of Qinghai-Xizang Plateau, Plateau Meteorology, 21(5), 514-517, 2002b.

Ma, Y., Su, Z., Koike, T., Yao, T., Ishikawa, H., Ueno, K., and Menenti, M.: On measuring and remote sensing surface energy partitioning over the Tibetan Plateau-from GAME/Tibet to CAMP/Tibet, Phys. Chem. Earth, 28, 63-74, 2003.

Ma, Y., Fan, S., Ishikawa, H., Tsukamoto, O., Yao, T., Koike, T., Zuo, H., Hu, Z., and Su, Z.: Diurnal and inter-monthly variation of land surface heat fluxes over the central Tibetan Plateau area, Theoretical Appl. Climatol., 80, 259-273, 2005.

Ma, Y., Yao, T., and Wang, J.: Experimental study of energy and water cycle in Tibetan Plateau-The progress introduction on the study of GAME/Tibet and CAMP/Tibet, Plateau Meteorology, 25(2), 344-351, 2006a.

Ma, Y., Zhong, L., Su, Z., Ishikawa, H., Menenti, M., and Koike, T.: Determination of regional distributions and seasonal variations of land surface heat fluxes from Landsat-7 Ehanced Thematic 
Mapper data over the central Tibetan Plateau area, J. Geophys. Res., 111, D10305, doi:10.1029/2005JD006742, 2006 b.

Ma, Y., Menenti, M., Feddes, R., and Wang, J.: Analysis of the land surface heterogeneity and its impact on atmospheric variables and the aerodynamic and thermodynamic roughness lengths, J. Geophys. Res., 113, D08113, doi:10.1029/2007JD009124, 2008.

Monin, A. S. and Obukhov, A. M.: Basic laws of turbulent mixing the atmospheric near the ground, Akad. Nauk. SSR., Geophiz. Inst., 24(151), 163-187, 1954.

Qiu, J.: The third pole, Nature, 454, 393-396, 2008.

Su, Z., Zhang, T., Ma, Y., Jia, L., and Wen, J.: Energy and water cycle over the Tibetan Plateau: surface energy balance and turbulent heat fluxes, Adv. Earth Sci., 21(12), 1224-1236, 2006.

Sun, F., Ma, Y., Ma, W., and Li, M.: One observational study on atmospheric boundary layer structure in Mt. Qomolangma region, Plateau Meteorology, 25(6), 1014-1019, 2006.

Sun, F., Ma, Y., Li, M., Ma, W., Tian, H., and Metzge, S.: Boundary layer effects above a Himalayan valley near Mount Everest, Geophys. Res. Lett., 34, L08808, doi:10.1029/2007GL029484, 2007a.

Sun, F. and Ma, Y.: Characteristics of local circulation in a Himalayan valley on the northern slop of Mt. Qomolangma, Plateau Meteorology, 26(6), 1187-1190, 2007b.

Tanaka, K., Ishikawa, H., Hayashi, T., Tamagawa, I., and Ma, Y.: Surface energy budget at Amdo on the Tibetan Plateau using GAME/Tibet IOP98 data, J. Meteor. Soc. Japan, 79(1B), 505$517,2001$.

Wang, J. and Mitsuta, Y.: Turbulence structure and transfer characteristics in the surface layer of the HEIFE Gobi area, J. Meteor. Soc. Japan, 69(5), 587-593, 1991.

Wang, S. and Ma,Y.: The Structure of Atmospheric Boundary Layer over Mount Qomolangma in Summer, Journal Glaciol. Geocryol., 30(4), 681-687, 2008.

Xu, X., Zhou, M., Chen, J., Bian, L., Zhang, G., Liu, H., Li, S., Zhang, H., Zhao, Y., Suolongduoji, and Wang, J.: A comprehensive physical pattern of land-air dynamic and thermal structure on the Qinghai-Xizang Plateau, Science in China (D), 32, 577 594, 2002

Yanai, M., Li, C. Y., and Song, Z.: Seasonal heating of the Tibetan Plateau and its effects on the evolution of the Asian summer monsoon, J. Meteor. Soc. Japan, 70, 319-351, 1992.

Yang, K., Koike, T., and Yang, D.: Surface Flux Parameterization in the Tibetan Plateau, Bound.-Lay. Meteorol., 106(2), 245-262, 2003.
Yang, K., Koike, T., Fujii, H., Tamura, T., Xu, X., Bian, L., and Zhou, M.: The daytime evolution of the atmospheric boundary layer and convection over the Tibetan Plateau: Observations and Simulations, J. Meteor. Soc. Japan, 82, 1777-1792, 2004.

Yang, K., Koike, T., Ishikawa, H., Kim, J., Li, X., Liu, H., Liu, S., Ma, Y., and Wang, J.: Turbulent flux transfer over bare-soil Surfaces: characteristics and parameterization, J. Appl. Meteorol. Clim., 46, 276-290, 2008.

Ye, D. and Gao, Y.: The Meteorology of the Qinghai-Xizang (Tibet) Plateau, Science Press, Beijing, 278 pp., 1979.

Ye, D.: Some characteristics of the summer circulation over the Qinghai-Xizang(Tibet) Plateau and its neighborhood, B. Am. Meteorol. Soc., 62, 14-19, 1981.

Ye, D. and Wu, G.: The role of the heat source of the Tibetan Plateau in the General circulation, Meteorol. Atmos. Phys., 67, 181-198, 1998.

Zhang, Q., Zhu, B., Zhu, F., Wang, D., Sun, G., Lu, J., Peng, Y., and Wang, Y.: Advances in the Qinghai-Xizang Plateau Meteorology, The Qinghai-Xizang Plateau Meteorological Experiment (1979) and Research, Science Press, 268pp., 1988.

Zhao, Y., Ma, Y., Ma, W., Li, M., Sun, F., Wang, L., and Xiang, M.: Variations of soil temperature and soil moisture in northern Tibetan Plateau, J. Glaciol. Geocryol., 29(4), 578-583, 2006.

Zhong, L., Ma, Y., Su, Z., Liu, X., Li, M., Ma, W., and Wang, Y.: Atmospheric turbulence and land-atmosphere energy transfer characteristics in the surface layer of the northern slope of Mt. Qomolangma area, Adv. Earth Sci., 21(12), 1293-1303, 2006.

Zhong, L., Ma, Y., and Li, M.: An analysis of atmospheric turbulent and energy transfer characteristics of surface layer over Rongbu Valley of Mt. Qomolangma area, Chinese J. Atmos. Sci., 31(1), 48-56, 2007a

Zhong, L., Ma, Y., Su, Z., Wang, Y., Lu, Y., and Zhu, Z.: Variation characteristics of meteorological elements, radiation and energy budget components before and after the rainy season in the surface layer of Mt. Qomolangma area, Plateau Meteorology, 26(6), 1269-1275, 2007b.

Zhu, Z., Ma, Y., Li, M., and Zhong, L.: Diurnal and seasonal variations of carbon dioxide over the alpine meadow ecosystem on the northern slope of the Qomolangma, Plateau Meteorology, 26(6), 1300-1304, 2007

Zuo, H., Hu, Y., Li, D., Lu, S., and Ma, Y.: Seasonal transition and its boundary characteristics in Anduo area of Tibetan Plateau, Prog. Nat. Sci., 15(3), 239-245, 2005. 